\title{
Thought on Connotation of Quality of Migrant Workers' Income
}

\author{
Niya Liu ${ }^{1,2}$ \\ ${ }^{1}$ Hebei Finance University Baoding 071051, , China \\ ${ }^{2}$ Agricultural University of Hebei, Baoding 071051, China
}

Keywords: Migrant workers; Quantity of income; Quality of income; Five Dimensions; Connotation

\begin{abstract}
In view of the background that the migrant workers bring great productivity and labor force for China, their income also attracts the social attention. This paper carries out definition and analysis on the quality of migrant workers' income from perspective of the cost, stability, structure, knowledge, and adequacy of migrant workers' income to further explore the connotation of quality of migrant workers' income for the purpose of helping readers to get a deep knowledge and understanding.
\end{abstract}

\section{Introduction}

The farmers' income growth is a core part of three rural issues at present. Meanwhile, as an important group of farmers, the migrant workers continuously expand their scale. According to relevant statistical data, the scale of migrant workers in 2012 was up to 263 million, which was increased by 3.9\% compared to the data in 2011; the number of outgoing migrant workers was 163 million, which was increased by $3 \%$ compared to last year; the number of migrant workers who went out with entire family was 338 million, and the increase rate was 2.9\%; among residents, the number of outgoing migrant workers was 129 million, with an increase rate of 3\%. The number of local migrant workers was up to 99.25 million, with an increase rate of 5.4\%. Through analysis on migrant workers' income, it could be seen that the migrant workers' monthly average income was RMB 2,290 yuan; compared to 2011, the per capita monthly income increased by RMB 214 yuan, with an increase rate of $11.8 \%$; however, the increment decreased by RMB 118 yuan compared to the same period of last year, and the increase rate decreased by 9.4\%. Currently, the migrant workers' income condition is closely linked with the objective of realizing common prosperity, which causes important influence on the development of China's national economy.

\section{Literature review}

The academic circle never ignores the hot topic of migrant workers. Through summary on previous scholars' research, the author has found that the research on migrant workers' income mainly focuses on following aspects. Firstly, it is the research on current situation of migrant workers' income. According to the monitoring and surveying report on migrant workers in 2012, it is shown that the farmers with high income mainly gather in large and medium-sized cities; meanwhile, as for migrant workers who engage in different industry, there is certain difference in their income, and it is able to see obvious different in the income level of migrant workers who engage in service industry, manufacturing industry, accommodation and catering industry and the income level of employed staffs and self-support personnel; compared to the income of migrant workers as urban residents, we can see distinct difference. Secondly, it is the research on the growth of farmers' income. Huang Qian (2010) thought that the change of work in industry could cause positive influence on the growth of low-income migrant workers' income, but cause negative influence on the growth of high-income migrant workers' income; furthermore, Huang Qian proposed that the change of work in industry could cause negative influence on the income of migrant workers at all income levels. ${ }^{[1]}$ Yao Jun (2010) thought that the different in migrant workers' wage caused by employment mobility determined different mechanism; through selecting mobile employment, it was able to mitigate the pressure of migrant workers' low wage to certain degree. ${ }^{[2]}$ Thirdly, it is the research on factors 
influencing migrant workers' income. Zhou Xiaogang (2012) thought that there were many aspects of factors influencing migrant workers' income, involving personal features (gender, age, and marital status, etc.), human capital features (level of education, health state, and mastery degree of professional skills, etc.), and working time. Besides, some scholars thought that the main factors which hindered the improvement in migrant workers' income included household registration system, medical insurance system, endowment insurance system, and unemployment insurance system, etc. ${ }^{\text {[3] }}$

In view of the fact that the progress of agricultural modernization is gradually quickened, the quality attribute of migrant workers' income also attracts more and more attention; the channels and structure of income source, the cost paid to obtain those incomes, the required professional knowledge, and other forms of elements can all influence migrant workers' ability of increasing income, labor cost, and employment structure; we can understand them as quality of income. Through analysis on previous and current research summary, it can be seen that the great progress has been made in the research on migrant workers' income; however, partial scholars still keep a foothold in dimension of exogenous variables, and the current research often focuses on common features of quantity of migrant workers' income and lacks of the features of quantity of migrant workers' income based on the background of labor transfer and in the process of rapid economic development; therefore, there lack of scholars who carry out research on the correlation between migrant workers' income and its cost, stability, and structure, and also lacks of analysis on the internal link between migrant workers' income and their acquisition cost.

\section{Relevant connotation of quality of migrant workers' income}

First of all, we shall clearly know that the migrant workers' income not only has quantitative stipulation, but also has qualitative stipulation. The high-quality migrant workers' income is often characterized by low acquisition cost, sufficient quantity, reasonable structure, high level of knowledge, and stable increase, etc. The author mainly carries out examination on the quality of migrant workers' income from five relevant dimensions, that is, cost (research on various kinds of cost consumed in the process of acquiring the income), stability (analysis on whether the migrant workers have stable source of income), structure (research on whether the migrant workers can obtain income from many means), knowledge (research on the relationship between level of knowledge required in acquiring income and work skills), and adequacy (research on whether the migrant workers' income can meet their family demand).

\section{Analysis on correlation between cost and quality of migrant workers' income}

In daily work and life, except for paying material goods, labor, and capital in normal production process, the migrant workers also need to pay other expenses caused in the process of seeking for job opportunity, and those expenses can be regarded as the cost which the migrant workers shall pay in order to obtain income. If the analysis on migrant workers' income is made only from perspective of quantity, most of scholars will select to weaken the acquisition cost or directly mix it with production cost. However, if we carry out analysis from perspective of quality of migrant workers' income, the true existence and function of acquisition cost will be hardly ignored; furthermore, there exists obvious reverse relation between acquisition cost and quality of migrant workers' income.

The transaction cost involved in the acquisition cost of migrant workers' income mainly includes the information cost, contractual seeking cost, and performance cost borne by migrant workers in the process of obtaining their income. Strictly speaking, the cost of social capital is also a part of transaction cost; however, based on the fact that the influence of social capital on quality of income exists in the initial link of obtaining the job opportunity, this paper doesn't give a uniform discussion on cost of social capital. Due to existence of dualistic economic structure in China, the farmers' position is at the lowest social level; in the daily work and life, they shall endure the identity and work discrimination, and can't obtain normal treatment in terms of employment right and interest; compared to urban workers, they have higher seeking cost and information cost. In addition, while obtaining their income, they often meet various barriers. For example, the wage that they shall obtain 
is not issued according to stipulated standard; even though the wage is issued, the issuing is not on time and not in full amount. Besides, there commonly exists the phenomenon that the material objects are utilized to replace the monetary wage, which causes great negative influence on the quality of migrant workers' income.

\section{Analysis on correlation between stability and quality of migrant workers' income}

The stability is another important dimension used to explain the quality of migrant workers' income. The economic instability with large fluctuation causes great harm on migrant workers' income, which increases the potential risk for migrant workers to be engaged in work on one hand and damages migrant workers' long-term and stable intrinsic income growth mechanism on the other hand. As a vulnerable group, the migrant workers lack of corresponding follow-up capital to confront large fluctuation; compared to rich people, the migrant workers have low ability to keep stable level of consumption. Meanwhile, due to lack of substitutive selection, the works that the migrant workers are engaged in are often largely influenced by economic fluctuation, and the common industry is construction industry and manufacturing industry. Therefore, their stability in life and work is affected by their instable income, which causes increasingly large gap between migrant workers and other social stratum. Currently, partial scholars think that there exists negative correlation between growth of income and excessively frequent fluctuation of income. Therefore, the author thinks that it is able to consider to suitable slow down the growth speed under the premise of ensuring that the migrant workers' income can be kept under stable growth and controlling their unemployment risk. However, when the fluctuation of migrant workers' income is beyond certain range, the risk in reducing the rate of income growth will obviously increase. In the conductive process, the direction of growth rate and fluctuation will show asymmetry and nonlinearity.

\section{Analysis on correlation between structure and quality of migrant workers' income}

As the migrant workers play a more and more important role in the transformation of dualistic economic structure, they play a very important function in promoting the economic development of developing countries. The economic growth needs structural transformation, and it is also restricted by structural deviation; meanwhile, the existence of structural deviation will hinder the improvement of quality of economic growth; therefore, the author suggests that the income shall make transformation from speed-based growth mode to structural mode so as to optimize structural adjustment and promote the growth of income. The structure of migrant workers' income is closely related to the quality of income, which is mainly reflected at following three aspects. Firstly, the efficiency of growth of migrant workers' income depends on whether the income structure can be effectively coordinated; secondly, the structural transformation of migrant workers' income belongs to the progress in the efficiency of migrant workers' income in essence; thirdly, whether the growth of migrant workers' income can be kept stably depends on whether the income structure can be coordinated. In particular, after the reform and opening-up, the fundamental changes have happened in the structure of growth of migrant workers' income, and their income source has formed diversified and market-oriented pattern.

\section{Analysis on correlation between knowledge and quality of migrant workers' income}

Mincer (2006) thought that the income was obviously influenced by training technology, level of education, and other human capital variables. ${ }^{[4]}$ In current era of knowledge-driven economy, the personal income is closely related to human capital, and the knowledge content also becomes the intrinsic decisive factor which ensures the quality of migrant workers' income. The knowledge content of migrant workers' income is always measured via two indexes, that is, level of education and skill training. Although the easy training only plays a not obvious function on migrant workers' income, the short-term regular training can still exert important decisive function. Among migrant workers of different level of education, the migrant workers with level of secondary vocational education has the highest personal yield. The migrant workers' rate of education yield and level of education show a reverse- $U$ relation, thus we can see that the secondary vocational education can 
exert positive promotion function on migrant workers' income, and the low level of education seriously hinders the improvement of quality of migrant workers' income.

\section{Analysis on correlation between adequacy and quality of migrant workers' income}

The adequacy of migrant workers' income refers to the situation about whether the migrant workers' total income can solve food and clothing and meet normal production and living expenditure of one family, that is, the quantity level of income. Over 30 years, the level of China's migrant workers' income has been greatly improved since the reform and opening-up. According to the relevant data of national monitoring and survey report on migrant workers in 2012, the level of per capital monthly income for national migrant workers was RMB 2,290 yuan, and the per capital monthly incomes for migrant workers in east China, central China, and west China were RMB 2,286 yuan, RMB 2,257 yuan, and RMB 2,226 yuan respectively; compared to any previous years, the migrant workers' income in different areas showed a rising trend. Actually, the increase of quantity of income depends on the improvement of quality of income which is the premise to ensure that the quantity can increase stably and continuously.

\section{Conclusion}

In conclusion, expect that the quantity of migrant workers' income is adequate, the cost, stability, structure, and knowledge all don't meet the standard of migrant workers' high-quality income; furthermore, the asymmetry between quantity and quality of migrant workers' income becomes more and more prominent, and the increase of quantity can't ensure the improvement of quality. The migrant workers' high-quality income not only requires certain quantity, but also requires wide channels of source, continuous and stable growth of income, low cost in obtaining income, reasonable income structure, and high level of knowledge, etc. Therefore, the research on quality of migrant workers' income involves wide fields; currently, the relevant research in China is still under exploratory research stage, and the experience is insufficient in terms of theory and actual work. Therefore, in order to truly implement the research on the quality of migrant workers' income, we still need joint efforts from personages of all circles.

\section{References}

[1] Huang Qain. Influence of Change of Work on Growth of Urban Migrant Workers' Income, Chinese Rural Economy, 2010 (09).

[2] Yao Jun: Types of Mobile Employment and Migrant Workers' Income - Empirical Data from Yangtze River Delta Manufacturing Industry, Chinese Rural Economy, 2010 (11).

[3] Zhou Xiaogang, Li Liqing. Analysis on Difference in Regional Division, Occupational Background, Household Register Features, and Level of Urban Migrant Workers’ Income Evidence from 106 Cities in China, Soft Science, 2012 (02).

[4] Shoshana Grossbard. Jacob Mincer: A Pioneer of Modern Labor Economics. Springer-Verlag New YorkInc,2006.

[5] Yuan Desheng. Influence of Migrant Workers’ Wage on Urban-rural Income Gap in China, Zhejiang: Zhejiang University of Finance \& Economics, 2013. 